\title{
Cardiorespiratory and metabolic responses to body mass-based squat exercise in young men
}

\author{
Miki Haramura', Yohei Takai ${ }^{*}$, Takaya Yoshimoto², Masayoshi Yamamoto ${ }^{1}$ and Hiroaki Kanehisa ${ }^{1}$
}

\begin{abstract}
Background: The purpose of this study was to quantify cardiorespiratory and metabolic responses to body massbased squat exercise, with specific emphasis on the relationships with the exercise duration.

Methods: Fifteen healthy young men performed body mass-based squat exercise as well as an incremental loaded bicycle test, which determine maximal oxygen uptake and maximal heart rate, with an interval of 2 days between the tests. During both tasks, oxygen uptake, blood lactate concentration (BLa), and heart rate (HR) were determined. Oxygen uptake in both tasks was divided by body mass $\left(\mathrm{VO}_{2}\right) \cdot \mathrm{VO}_{2}$ in the squat task was normalized to $\mathrm{VO}_{2}$ in the incremental test $\left(\% \mathrm{VO}_{2}\right.$ max). In addition, electromyograms (EMGs) were also recorded from the vastus lateralis, rectus femoris, vastus medialis, biceps femoris, and gluteus maximus.

Results: Cardiorespiratory parameters and BLa did not change after 5 min from the exercise onset. The $\% \mathrm{VO}_{2} \max$ and BLa during body mass-based squat exercise were significantly related to maximal $\mathrm{VO}_{2}$ obtained by the incremental test. Metabolic equivalents reached 6.5 when the squat exercise was continuously performed for 5 min.

Conclusions: These findings indicate that (1) the squat exercise adopted here is of moderate intensity and predominantly uses aerobic energy supply after $5 \mathrm{~min}$ from the start of the exercise and (2) relative intensity during the exercise depends on an individual's maximal aerobic power.
\end{abstract}

Keywords: Resistance exercise, Lactate threshold, Oxygen uptake, Aerobic metabolism, Electromyograms

\section{Background}

It is well known that a training program consisting of many repetitions with low load is an effective maneuver for developing local muscular endurance [1]. Recently, Miyamoto et al. [2] have observed that 4 weeks of lowintensity electrical muscle stimulation into the knee extensors improved peak oxygen uptake and ventilatory threshold during incremental bicycle exercise. This suggests that low intensity and high repetition resistance training can enhance not only local but also systemic endurance capacities. In addition, many studies have tried to determine lactate threshold (LT) at which glycolytic metabolism is enhanced and energy supply shifts from aerobic to glycolytic metabolism [3], by using

\footnotetext{
* Correspondence: y-takai@nifs-k.ac.jp

${ }^{1}$ Sports and Life Science, National Institute of Fitness and Sports in Kanoya, 1

Shiromizu, Kanoya, Kagoshima 891-2393, Japan

Full list of author information is available at the end of the article
}

incremental resistance exercises of the lower extremities [4-8]. It has been shown that LT intensities during half squats [8] and leg press [4-6] exercises were 25 and $27 \%$ of one repetition maximum (1RM), respectively. When the squat exercise at the corresponding intensity is conducted continuously for $30 \mathrm{~min}(30 \mathrm{~s}$ active with an interval of $1 \mathrm{~min} \times 20$ sets), respiratory response and blood lactate concentration during the exercise appear to be stable after 3 to 6 min from task onset, indicating that squat exercise at LT intensity is predominantly aerobic in nature [6]. Exercise at LT intensity can be conducted continuously without blood lactate accumulation because of equilibrium between the rate of lactate appearance into and disappearance from the blood occurs, reflecting a predominance of aerobic metabolism $[9,10]$.

It is known that body mass-based exercise training (e.g., squat, calf raise, and hip flexion exercises) is feasible and effective for improving muscular strength of the 
knee extensors in elderly populations $[11,12]$ and percent body fat, muscular strength of the knee extensors, and jump performance in adolescences $[13,14]$. A training scheme consisting of body mass-based exercise has some advantages in that everyone can perform such exercises anywhere with no special apparatus. However, prior studies have provided less information concerning cardiorespiratory and metabolic responses to body massbased squat exercise. Isear et al. [15] have reported that, for young men, activity level of the vastus lateralis during body mass-based parallel squat exercise was 33\% of that observed during maximal voluntary contraction. Taking this into account together with the reports of Garnacho-Castano et al. [8] and de Sousa et al. [6], it may be assumed that, at least for young adults, body mass-based squat exercise would be predominately supported via aerobic metabolism when it is performed continuously.

The purpose of this study was to quantify cardiorespiratory and metabolic responses to body mass-based squat exercise, with specific emphasis on the association with the exercise duration. To this end, we mainly focused the exercise times at which the measured variables reached the stable conditions and the magnitude of the measured variables at the corresponding times. As mentioned above, the previous studies that examined the effects of body mass-based exercise training have focused on improvement in muscle function and body composition. The findings obtained here will be useful for discussing whether or not body mass-based exercise can be a training modality for improving not only muscular endurance but also cardiorespiratory function.

\section{Methods}

\section{Subjects}

Fifteen healthy men (age, $24.2 \pm 4.8$ years; height, 171.2 $\pm 5.1 \mathrm{~cm}$; body mass, $65.4 \pm 7.4 \mathrm{~kg}$; percent body fat, $16.0 \pm 4.4 \%$, means \pm SDs) participated in this study. Physical characteristics of the subjects are presented in Table 1. All subjects were involved in physical activities such as jogging and cycling for at least $3 \mathrm{~h}$ per week, but they did not perform regular resistance training. All subjects were free of long-term use of oral steroids use or other medications that can influence weight gain, multiple food allergies, moderate or substantial physical or developmental disability, or infection. They refrained from eating, smoking, or drinking tea or coffee for $2 \mathrm{~h}$ prior to the test. This study was approved by the ethical committee of the National Institute of Fitness and Sports in Kanoya. Prior to the experiment, all subjects were informed of the purpose and procedures of the study and possible risks. Written informed consent was obtained from all subjects.
Table 1 Physical characteristics of subjects

\begin{tabular}{ll}
\hline Age, years & $24.2 \pm 4.8$ \\
Body mass, kilograms & $65.4 \pm 7.4$ \\
Height, centimeters & $171.2 \pm 5.1$ \\
Percent body fat, \% & $16.0 \pm 4.4$ \\
KET/BM, newton-meter per kilogram & $3.0 \pm 0.9$ \\
BLa at LT, millimoles per liter & $2.3 \pm 0.5$ \\
\%VO 2 max at LT, \% & $46.5 \pm 6.2$ \\
\%HRmax at LT, \% & $65.8 \pm 4.8$
\end{tabular}

Data are presented as means \pm SDs

KET/BM knee extension torque relative to body mass, BLa blood lactate concentration, $L T$ lactate threshold, $\% \mathrm{VO}_{2}$ max oxygen uptake during squat exercise relative to maximal oxygen uptake, \%HRmax heart rate during squat exercise relative to maximal heart rate

\section{Experimental design}

Subjects participated in two experimental sessions with an interval of 2 days between sessions. An incremental loaded bicycle test was conducted to determine maximal oxygen uptake $\left(\mathrm{VO}_{2} \max \right)$ and maximal heart rate (HRmax) in the first session. In the second session, subjects continuously performed 200 times body massbased squat exercises. Respiratory gas, heart rate, blood lactate concentration, knee joint angle, and muscular activity were measured during both sessions.

\section{Incremental loaded bicycle test}

The incremental test was conducted in accordance with the procedure used by James et al. [16], using an electrically braked bicycle ergometer (COMBI, AEROBIKE75XLIII, Tokyo, Japan). After a 5-min rest, subjects pedaled the bicycle with an initial load of $75 \mathrm{~W}$. The load was incrementally increased by $25 \mathrm{~W}$ every $3 \mathrm{~min}$ until exhaustion. Pedaling frequency was held constant at $60 \mathrm{rpm}$ with the aid of an audible metronome. We set the following criteria to judge termination of the test: (1) oxygen uptake was at a steady state, (2) rating of perceived exhaustion (RPE) was 19 or 20, (3) subjects were unable to maintain a pedaling rate of $60 \mathrm{rpm}$, (4) respiratory exchange ratio (RQ) $>1.15$, and (5) heart rate was at steady state (estimated value $\pm 15 \mathrm{bpm}$ ) [17].

\section{Body mass-based squat exercise}

Subjects continuously performed a body mass-based squat exercise, completing 200 repetitions. The squat task was conducted at a tempo of $45 \mathrm{rpm}$ ( 2 beats/time) which allows subjects to carry it out correctly [18]. Subjects stood with their legs to shoulder width and squatted with the knee joint flexed at $90^{\circ}$ from standing position, and then returned to initial position. A box was put behind the subjects to control range of motion during the squat task. Subjects were asked to pull their hip behind, and not to lean their trunks forward and move their knees forward, and stop the motion when changing 
from ascending (descending) to descending (ascending) phases during the task.

\section{Respiratory gas}

During the tasks, respiratory gas was collected continuously to determine oxygen uptake $\left(\mathrm{VO}_{2}\right)$, carbon dioxide production $\left(\mathrm{VCO}_{2}\right)$, minute ventilation $(\mathrm{VE})$, and respiratory exchange ratio. Before the experiment commenced, flow volume calibration and oxygen gas calibration were performed using an automated breath-by-breath system that was previously calibrated (Vmax Specrta 229, Sensor medics Corp., Yorba Linda, CA, USA). During the incremental test, $\mathrm{VO}_{2}$ max was taken to be the mean $\mathrm{VO}_{2}$ over the final $30 \mathrm{~s}$ of the incremental phase [19]. During the squat exercise, respiratory gas data was averaged for each 1 min epoch. $\mathrm{VO}_{2}$ during both tasks was normalized to body mass. The $\mathrm{VO}_{2}$ during the squat task was normalized to $\mathrm{VO}_{2} \mathrm{max}$ and expressed as relative value $\left(\% \mathrm{VO}_{2} \mathrm{max}\right)$. Metabolic equivalents (METs) during the body massbased squat exercise were calculated from metabolic rate at rest $(3.5 \mathrm{ml} / \mathrm{kg} / \mathrm{min})[20,21]$ and $\mathrm{VO}_{2}$ during the squat exercise.

\section{Heart rate}

Heart rate (HR) was monitored every $1 \mathrm{~s}$ using telemetry (Polar RC3 GPS, Polar Electro OY; Kempele, Finland). HR was averaged over every $1 \mathrm{~min}$, and normalized to HRmax, and expressed as relative value (\%HRmax).

\section{Blood lactate concentration}

Blood sample $(0.3 \mu \mathrm{l})$ was collected from the fingertip using a portable digital Lactate Pro meter (Lactate Pro2, LT-1730, ARKRAY Factory Inc, Kyoto, Japan) and in the last $30 \mathrm{~s}$ of each stage during the incremental load test. Blood lactate concentration (BLa) was averaged over every 1 min during the squat exercise. The LT was estimated using the algorithm adjustment method [5] and based on the procedure described by Orr et al. [22], as work intensity at which lactate concentrations start to increase in an exponential manner [23].

\section{Knee joint angle}

To determine the ascending and descending squat exercise phases, knee joint angles were recorded using an electronic goniometer (SG-150, Biometrics, Gwent, UK). The goniometer was attached to the lateral side of the thigh and lower leg with adhesive tape. Joint angle signals were recorded and stored via a 16-bit analog/digital converter (PowerLab/16S, ADInstruments, Sydney, Australia) on a personal computer at a sampling frequency of $2 \mathrm{kHz}$.

\section{Electromyogram}

During both maximal voluntary contraction (MVC) and squat tasks, surface electromyograms (EMGs) (ME6000T, MEGA Electronics, Finland) with Ag-AgCl electrodes (diameter $10 \mathrm{~mm}$; interelectrode distance $20 \mathrm{~mm}$ ) (N-00-S, Blue Sensor M, Ambu, Denmark) were recorded from the vastus lateralis $(\mathrm{VL})$, rectus femoris $(\mathrm{RF})$, vastus medialis $(\mathrm{VM})$, biceps femoris $(\mathrm{BF})$, and gluteus maximus (GM) muscles from the right leg. After the skin surface was shaved, rubbed with sandpaper, and cleaned with alcohol, the electrodes were attached to the skin over the muscle belly to the direction of fascicles at the same location between days, according to the method reported by Tillin et al. [24]. The electrode locations were at 55\% (VL), 50\% (RF), 90\% (VM), and 45\% (BF) of the distance between the greater trochanter and the lateral femoral condyle. The location of each electrode was marked on the skin surface with a permanent maker. A ground electrode (preamplifer) was attached near the two electrodes. EMG signals were collected at a sampling frequency of $2 \mathrm{kHz}$ and stored on a personal computer. EMG signals and MVC torques is obtained from the right side. To normalize muscular activity during the squat task, the subject exerted MVC in each muscle. For the MVC tasks, subjects gradually exerted each torque from baseline to maximum and then sustained at maximum for approximately $2 \mathrm{~s}$. Subjects performed two trials, with a 3-min interval between trials. To determine maximal EMG amplitudes of the knee extensors and flexors, subjects exerted knee extension and flexion torques with a dynamometer (Biodex System 2; Biodex Medical Systems, NY, USA). Subjects were fixed on an adjustable chair with hip and knee joints flexed at $90^{\circ}$. To prevent the joint angle from changing during the tasks, the trunk and hips were fixed using non-elastic belts. To quantify maximal GM EMG amplitude, subjects produced hip extension torque using a custom-made device (AO-2T, Applied Office, Japan) equipped with tension/compression load cells (LUR-ASA1, Kyowa, Japan). Subjects lay down prone on a bed with their knee joint flexed at $90^{\circ}$. To prevent the joint angle from changing during the task, the trunk and hips were fixed by non-elastic belts. An additional trial was conducted if the difference in the peak values between the trials was more than $10 \%$. The trial with the highest peak force was adopted for further analysis. MVC torques were normalized to body mass.

Root-mean-square (RMS) was calculated from the EMG amplitudes of each muscle during the MVC and squat tasks, using data analysis software (Chart version 7; ADInstruments, Australia). In the MVC task, the RMS value $\left(E_{M} G_{M V C}\right)$ was determined over a 1-s window centered at the time at which peak torque was attained (Fig. 1a). In the squat task, the RMS value was 

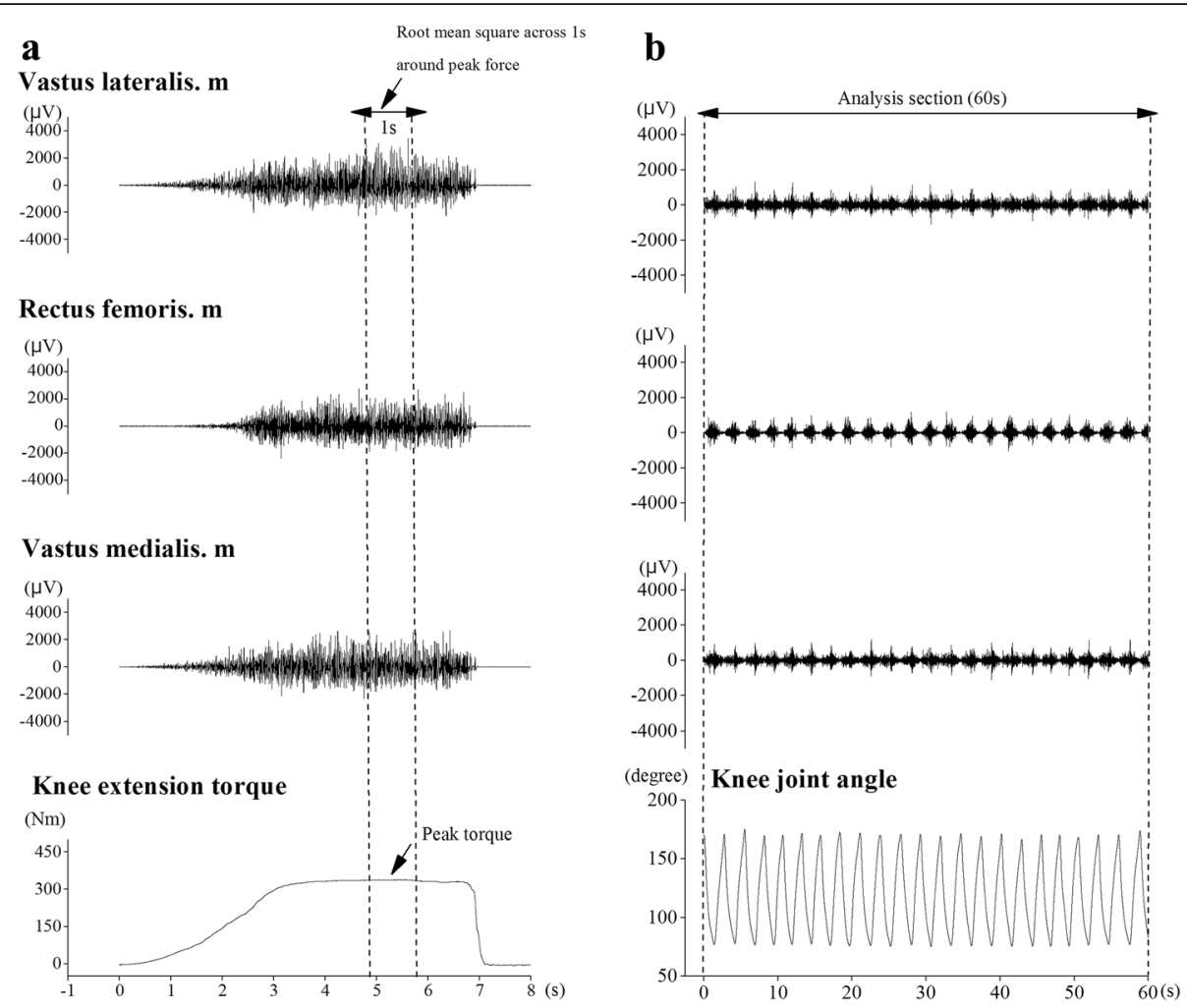

Fig. 1 Example data of the MVC task data for knee extension (a) and body mass-based squat exercise (b)

determined over a 1-min window (Fig. 1b). The RMS value during the squat task was normalized to $\mathrm{EMG}_{\mathrm{MVC}}$ and expressed as a relative value (\%EMG $\mathrm{MVC}_{\mathrm{MC}}$ ).

In our preliminary study, seven young men performed MVCs twice with an interval of 7 days to confirm the reproducibility of MVC measurements. As the results, intra-class correlation coefficients were $\geq 0.88$ for MVC torques, and $\geq 0.79$ for EMG amplitudes during the MVCs, satisfying a criteria for reproducibility of the measurement $(>0.75)$ [25].

\section{Statistical analysis}

Descriptive data are presented as means \pm SDs. Prior to the experiment, we have estimated sample size based on Cohen's criteria (effect size, 0.40; an $\alpha$ level, 0.05; a power $(1-\beta), 0.95)$ [26] by using statistical software (G*Power 3.1.9.2, Heinrich-Heine-Universitat Düsseldorf, Düsseldorf, Germany; http://www.gpower.hhu.de/). The results revealed that at least nine subjects were necessary as the total sample size. Independent variables were $\mathrm{VO}_{2}, \% \mathrm{VO}_{2} \max$, METs, VE, RQ, HR, \%HRmax, $\mathrm{BLa}$, and $\% \mathrm{EMG}_{\mathrm{MVC}}$. Mauchly's test of sphericity was used to confirm variable homogeneity. To test for significant time-related differences in these variables during the body mass-based squat exercise, one way analysis of variance (ANOVA) with repeated measures was used. When appropriate, Bonferroni tests were used for post hoc comparisons. In this study, we defined the condition in which the measured variable did not significantly differ between adjacent time points as stable condition. Pearson's product-moment correlation coefficient $(r)$ was calculated for relationships between $\mathrm{VO}_{2}$ max and each of $\mathrm{BLa}$ and $\% \mathrm{VO}_{2} \max$ during the squat task (4 to $9 \mathrm{~min})$. BLa and $\% \mathrm{VO}_{2} \max$ data averaged in stable condition, respectively. Furthermore, we examined significance of $r$ on the relationships between $\% \mathrm{EMG}_{\mathrm{MVC}}$ of each muscle and MVC torque relative to body mass. The $\% \mathrm{EMG}_{\mathrm{MVC}}$ data averaged in stable condition in this analysis. Statistical significance was set at $p<0.05$. All data were analyzed using statistical software (SPSS statistics 22; IBM, Tokyo, Japan).

\section{Results}

The mean values for cardiorespiratory and metabolic parameters at LT during the incremental test were $2.3 \pm$ $0.5 \mathrm{mmol} / \mathrm{L}$ for $\mathrm{BLa}, 46.5 \pm 6.2 \%$ for $\% \mathrm{VO}_{2} \max$, and $65.8 \pm 4.8 \%$ for $\%$ HRmax (Table 1 ).

\section{Cardiorespiratory response during body mass-based squat exercise}

$\mathrm{VO}_{2}, \% \mathrm{VO}_{2} \mathrm{max}$, and METs at $1 \mathrm{~min}$ from the exercise onset were significantly lower than those at other exercise time points, and significantly elevated until $4 \mathrm{~min}$ $(p<0.05)$. However, these variables did not significantly 
change after $5 \mathrm{~min}$ from the exercise onset (Fig. 2). The average values from 5 to $9 \mathrm{~min}$ were $22.7 \pm 3.9 \mathrm{ml} / \mathrm{kg} /$ min for $\mathrm{VO}_{2}, 46.2 \pm 9.7 \%$ for $\% \mathrm{VO}_{2} \max$, and $6.5 \pm 1.1$ for METs. Time courses of $\mathrm{VCO}_{2}$ and $\mathrm{VE}$ were similar to those of $\mathrm{VO}_{2}$ and $\% \mathrm{VO}_{2}$ max. The average values across 5-9 min were $1.6 \pm 0.4 \mathrm{~L} / \mathrm{min}$ for $\mathrm{VCO}_{2}$ and $35.0 \pm$ $8.8 \mathrm{~L} / \mathrm{min}$ for VE. RQ significantly increased until the second time point $(p<0.05)$, but did not change from 3 to $9 \min (1.1 \pm 0.1)$.

Time courses of HR and \%HRmax during body massbased squat exercise are presented in Fig. 3. HR and \%HRmax at $1 \mathrm{~min}$ from the exercise onset were significantly lower than those at other exercise time points, and significantly elevated until $6 \mathrm{~min}(p<0.05)$. In these variables, however, there were no significant differences

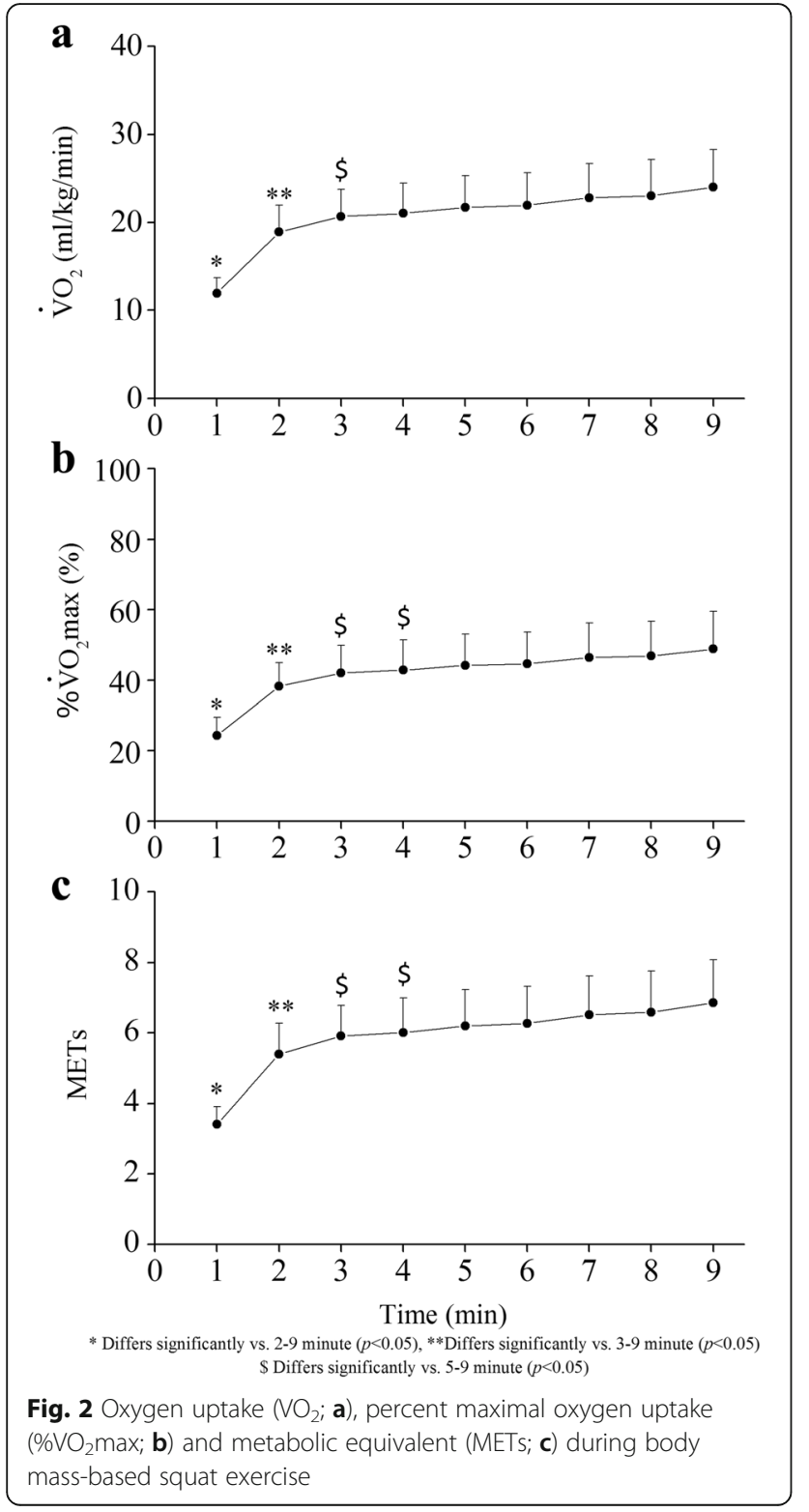

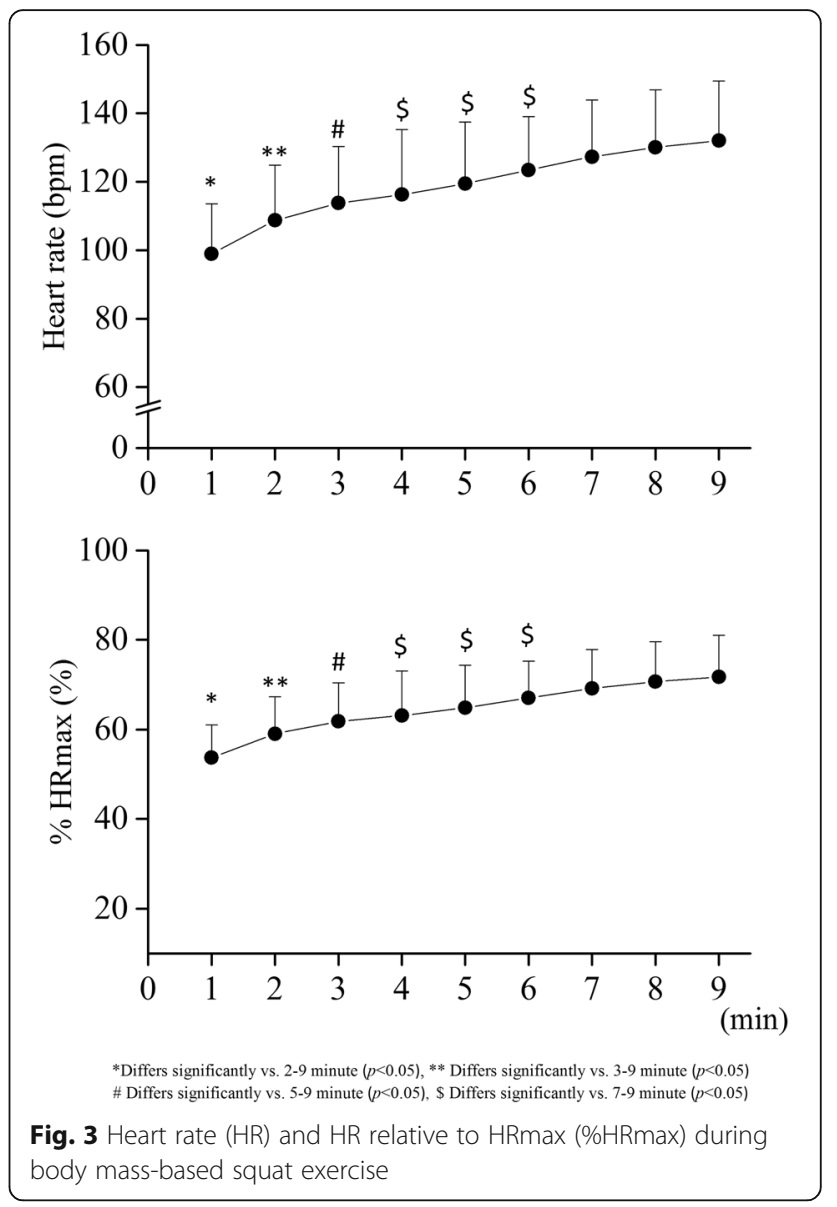

in any combination across exercise time points during a duration from 7 to $9 \mathrm{~min}$. The average values from 7 to 9 min were $131.1 \pm 17.1 \mathrm{bpm}$ and $71.2 \pm 9.0 \% \mathrm{HRmax}$, respectively. $\% \mathrm{VO}_{2} \max$ during the squat exercise across 5-9 min time points was negatively related to $\mathrm{VO}_{2} \max$ $(r=-0.561, p<0.05)$. The relationship between \%HRmax during the squat exercise across 7-9 min time points and $\mathrm{VO}_{2}$ max was not significant.

\section{BLa during body mass-based squat exercise}

BLa was the lowest at 1 min during the exercise (Fig. 4, $p<0.05)$. BLa values at 2 and $3 \mathrm{~min}$ were lower than those at 5, 8 , and $9 \mathrm{~min}(p<0.05)$, respectively. There was no significant increase in BLa after 3 min from the exercise onset. The average value across 3-9 min was $3.6 \pm 2.2 \mathrm{mmol} / \mathrm{L}$. BLa during the body mass-based squat exercise across 3-9 min time points was negatively related to $\mathrm{VO}_{2} \max (r=-0.582, p<0.05)$.

\section{$\% \mathrm{EMG}_{\mathrm{Mvc}}$ during body mass-based squat exercise}

Time courses of $\% \mathrm{EMG}_{\mathrm{MVC}}$ during body mass-based squat exercise are presented in Fig. 5. The $\% \mathrm{EMG}_{\mathrm{MVC}}$ of $\mathrm{VL}, \mathrm{RF}, \mathrm{VM}, \mathrm{BF}$, and GM at $1 \mathrm{~min}$ from the exercise onset were significantly lower as compared to those at 


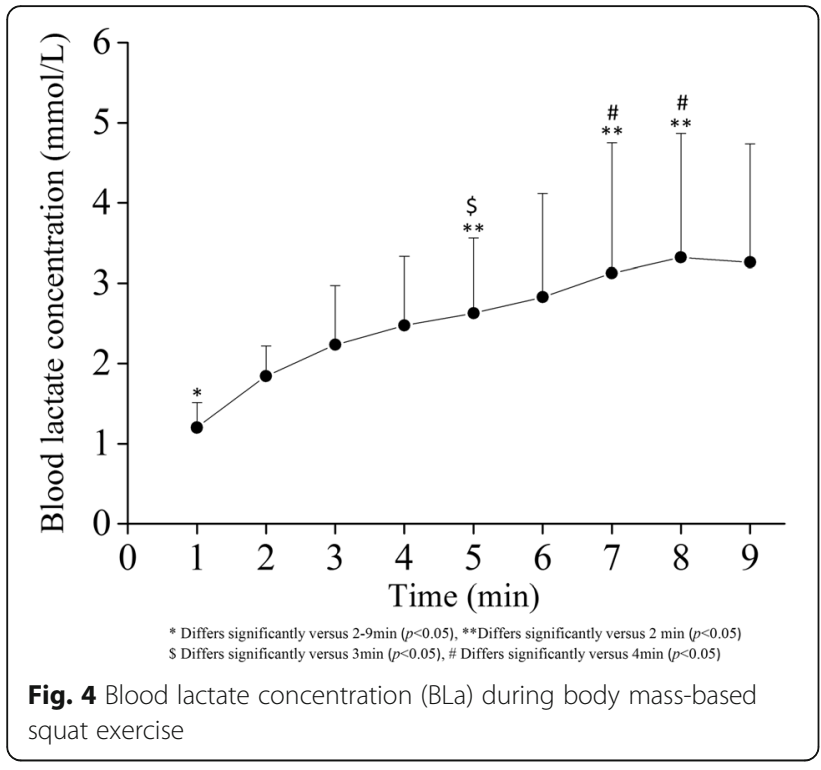

other exercise time points. These variables had no significant differences in any combination across exercise time points during a duration between 6 and $9 \mathrm{~min}$. The $\% \mathrm{EMG}_{\mathrm{MVC}}$ of VL $\left(45.0 \pm 17.9 \% \mathrm{EMG}_{\mathrm{MVC}}\right)$ and BF $(6.3 \pm$ $3.7 \% \mathrm{EMG}_{\mathrm{MVC}}$ ) is significantly higher after $6 \mathrm{~min}$ from exercise onset compared to those values across 1-5 $\mathrm{min}$ $\left(40.6 \pm 18.0 \% \mathrm{EMG}_{\mathrm{MVC}}\right.$ for $\mathrm{VL}$ and $5.3 \pm 3.2 \% \mathrm{EMG}_{\mathrm{MVC}}$ for $\mathrm{BF}$ ). The $\% \mathrm{EMG}_{\mathrm{MVC}}$ values for RF, VM, and GM $\left(31.4 \pm 15.0 \% \mathrm{EMG}_{\mathrm{MVC}}\right.$ for RF, $39.6 \pm 17.3 \% \mathrm{EMG}_{\mathrm{MVC}}$ for $\mathrm{VM}, 9.3 \pm 4.1 \% \mathrm{EMG}_{\mathrm{MVC}}$ for $\mathrm{GM}$ ) were higher than those at $1-5 \mathrm{~min} \quad\left(28.7 \pm 13.4 \% \mathrm{EMG}_{\mathrm{MVC}}\right.$ for $\mathrm{RF}, 34.8 \pm$ $16.2 \% \mathrm{EMG}_{\mathrm{MVC}}$ for $\mathrm{VM}, 8.4 \pm 4.0 \%$ for $\left.\mathrm{GM}\right)$, respectively. The $\% \mathrm{EMG}_{\mathrm{MVC}}$ of each muscle was not significantly related to the cardiorespiratory parameters during the squat exercise. The $\% \mathrm{EMG}_{\mathrm{MVC}}$ for VL during the body mass-based squat exercise was negatively related to knee extension torque relative to body mass (KET/ BM) $(r=-0.627, p<0.05)$. For RF and VM, the corresponding relationships were not significant $(r=-0.175$ 0.268 , n.s.).

\section{Discussion}

The main findings of this study were that (1) cardiorespiratory and BLa significantly increased until $4 \mathrm{~min}$ from the start of body mass-based exercise, but did not further change after $5 \mathrm{~min}$ and (2) $\% \mathrm{VO}_{2} \max$ and BLa during the squat exercise were negatively correlated with $\mathrm{VO}_{2}$ max. These findings indicate that body mass-based squat exercise is conducted predominantly using an aerobic energy supply after $5 \mathrm{~min}$ from the start of the exercise, and that the magnitude of aerobic and anaerobic metabolisms during the exercise depends on an individual's maximal aerobic power.
$\mathrm{VO}_{2} \max , \mathrm{VE}$, and $\mathrm{BLa}$ during the squat exercise did not significantly change after 5 min from exercise onset. Respiratory response is related to increases in metabolic products such as carbon dioxide and blood lactate in active muscle $[27,28]$ These metabolic products stimulate peripheral and central chemoreceptors and occurs ventilatory facilitation [27]. Considering earlier findings, the lack of significant changes in $\mathrm{VO}_{2} \mathrm{max}$ and $\mathrm{VE}$ after 5 min from exercise onset may be due to the fact that BLa did not change over the corresponding periods. Furthermore, low or moderate effort exercise can be maintained for a relatively long time, because blood lactate concentration is an equilibrium between rate of lactate appearance into and disappearance from the blood during exercises $[9,10]$, indicating that energy for the exercise is supplied largely via aerobic metabolism [29].

Oxygen uptake averaged across 5-9 min from exercise onset was $22.7 \pm 3.9 \mathrm{ml} / \mathrm{kg} / \mathrm{min}\left(46.2 \% \mathrm{VO}_{2} \max \right)$. This value is equivalent to that for squat exercise at LT intensity $(25 \mathrm{ml} / \mathrm{kg} / \mathrm{min})$ [8]. Furthermore, $\% \mathrm{VO}_{2} \mathrm{max}$ at LT during the incremental loaded bicycle test was $46.5 \pm$ $6.2 \%$, being similar to that obtained during the body mass-based squat exercise. The $\mathrm{VO}_{2}$ during the body mass-based squat exercise $(22.7 \pm 3.9 \mathrm{ml} / \mathrm{kg} / \mathrm{min})$ was similar to another value obtained during half squat exercise with a load of approximately $30 \% 1 \mathrm{RM}(18.3 \mathrm{ml} / \mathrm{kg} /$ min) [5]. This indicates that cardiorespiratory response to the body mass-based squat exercise is similar to that for squat exercise with an LT intensity external load. METs during the body-mass based squat exercise was $6.5 \pm 1.1$, corresponding to moderate aerobic exercise such as jogging and moderate aerobic dancing [30]. Taken together, we may say that, from the viewpoint of cardiorespiratory response, body mass-based squat exercise becomes a moderate intensity task when it is continued for at least for $5 \mathrm{~min}$.

$\% \mathrm{VO}_{2} \mathrm{max}$ and $\mathrm{BLa}$ during the body mass-based squat exercise were both significantly related to $\mathrm{VO}_{2} \max$. This result indicates that oxygen uptake and metabolic response during the squat exercise may depend on maximal aerobic power. In other words, these current results imply that a person with higher $\mathrm{VO}_{2} \max$ can conduct body mass-based squat exercise with relative low physiological load. Higher aerobic power may be attributed to greater mitochondrial numbers, greater mitochondrial density, and higher oxidation ability in active muscle [31]. In the present results, however, the $\mathrm{VO}_{2}$ during the squat exercise was not significantly related to $\mathrm{VO}_{2} \max$ $(r=0.010, p=0.970)$. This implies that the absolute oxygen uptake during the exercise is almost the same regardless of the magnitude of $\mathrm{VO}_{2}$ max.

The mean value of $\% \mathrm{EMG}_{\mathrm{MVC}}$ during the squat exercise was $40.6 \%$ for $\mathrm{VL}, 28.7 \%$ for RF, 34.8\% for VM, 5.3\% for BF, and $8.4 \%$ for GM. These values are equivalent to 

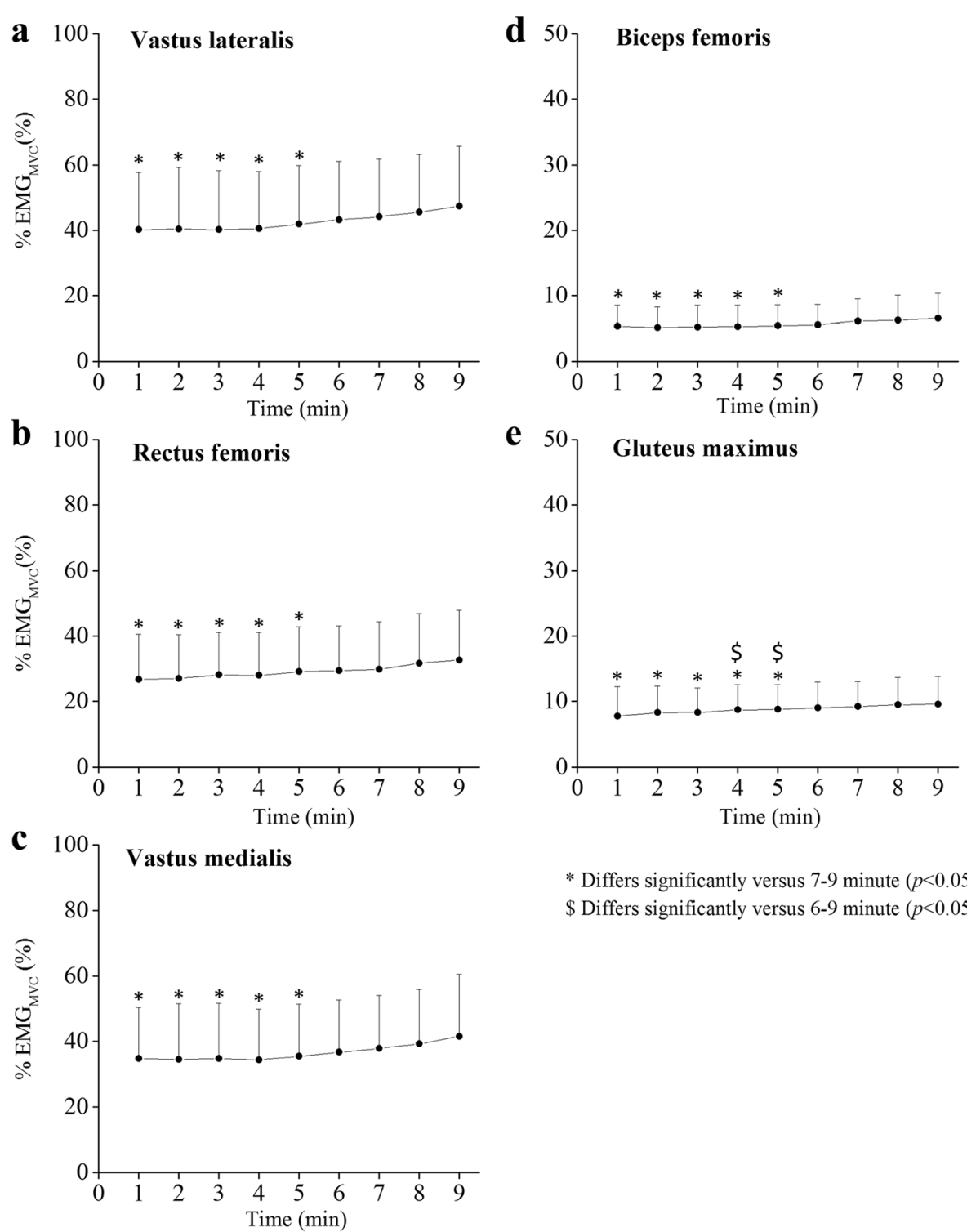

* Differs significantly versus 7-9 minute $(p<0.05)$
\$ Differs significantly versus 6-9 minute $(p<0.05)$

Fig. 5 \% EMG $\mathrm{MVC}_{\mathrm{V}}$ in lower extremity muscles during body mass-based squat exercise. a Vastus lateralis. b Rectus femoris. c Vastus medialis. d Biceps femoris. e Gluteus maximus

those reported by Isear et al. [15] who examined EMG activities during body mass-based squat exercise (33.1\%EMG $\mathrm{EVC}_{\mathrm{MVC}}$ for $\mathrm{VL}, 40.0 \% \mathrm{EMG}_{\mathrm{MVC}}$ for $\mathrm{RF}$, and $10.8 \% \mathrm{EMG}_{\mathrm{MVC}}$ for $\left.\mathrm{GM}\right)$. In the present study, the $\% \mathrm{EMG}_{\mathrm{MVC}}$ during the squat exercise significantly increased after 6 min from exercise onset. Because oxygen uptake is positively related to integrated EMG activity during an incremental loaded bicycle test [32], increases in integrated EMG, being derived from the number of action potentials and contracting muscle fibers [33], may be associated with elevated oxygen uptake during exercises. However, in the present results, the $\% \mathrm{EMG}_{\mathrm{MVC}}$ during the squat exercise increased in the later stages of the exercise, whereas oxygen uptake did not significantly shift after $5 \mathrm{~min}$ in this study. This might be due to the degree of increases in muscular activities during the exercise. In fact, the differences between the values averaged after $6 \mathrm{~min}$ and the values averaged over 1-5 $\mathrm{min}$ were $3.5-7.6 \% \mathrm{EMG}_{\mathrm{MVC}}$ for each muscle, indicating relatively small.

The $\% \mathrm{EMG}_{\mathrm{MVC}}$ for VL during body mass-based squat exercise was significantly related to KET/BM. This result supports our previous findings that the muscular activity levels of lower limb muscles during body mass-based exercises are negatively related to knee extension torque relative to body mass $[11,34]$. This implies that relative effort during body mass-based squat exercise is greater in a person with low force-generating capacity than one 
with high force-generating capacity. Considering that increase in relative load during the incremental loaded bicycle test linearly elevates oxygen uptake and integrated EMG activity [32], \% $\mathrm{VO}_{2}$ max would be expected to depend on the muscular activity level during the squat exercise. However, the corresponding relationships were not significant in this study. Therefore, at least in young men, cardiorespiratory responses during body massbased squat exercise may be independent of the muscular activity level of the knee extensors.

Because the design of this study was cross-sectional study, it is unclear whether body mass-based squat exercise training improves systemic and local endurance capacities. Miyamoto et al. [2] revealed that a 4-week intervention with low-intensity electrical muscle stimulation during knee extension exercises, corresponding to 3-4 METs, enhanced oxygen uptake during cycle ergometer. In the present study, METs during the body mass-based squat exercise reached $6.5 \pm 1.1$, and mainly activated the knee extensors. Body mass-based squat exercise may be one feasible approach for improving systemic and local endurance capacity when it is performed continuously at least for $5 \mathrm{~min}$.

\section{Conclusions}

From the viewpoint of cardiorespiratory and metabolic responses, body mass-based squat exercise is moderate intensity and is performed via aerobic metabolism after 5 min from exercise onset. Furthermore, the relative intensity of the squat exercise partially depends on the individual's aerobic maximal power.

\begin{abstract}
Abbreviations
\%EMG MVC: $_{\text {: }}$ GG amplitude relative to $E M G_{M V C}$ \%HRmax: HR relative to $\mathrm{HRmax} ; \% \mathrm{VO}_{2}$ max: $\mathrm{VO}_{2}$ relative to $\mathrm{VO}_{2}$ max; ANOVA: Analysis of variance; BF: Biceps femoris; BLa: Blood lactate concentration; EMG: Electromyogram; EMG MVC: EMG amplitude during MVC; GM: Gluteus maximus; HR: Heart rate; HRmax: Maximal heart rate; KET: Knee extension torque; LT: Lactate threshold; METs: Metabolic equivalents; MVC: Maximal isometric voluntary contraction; RF: Rectus femoris; RMS: Root-mean-square; RPE: Rating of perceived exhaustion; RQ: Respiratory exchange ratio; $\mathrm{VCO}_{2}$ : Carbon dioxide production; VE: Minute ventilation; VL: Vastus lateralis; VM: Vastus medialis; $\mathrm{VO}_{2}$ : Oxygen uptake; $\mathrm{VO}_{2}$ max: Maximal oxygen uptake
\end{abstract}

\section{Acknowledgements}

This study was supported by a NIFS project for designing school-based exercise training for promoting fitness and cognitive functioning in children. The authors thank the teachers of the pilot study schools in Kagoshima and students of National Institute of Fitness and Sports in Kanoya for their contributions.

\section{Authors' contributions}

MH participated in the study design and cardiorespiratory and metabolic response measurements and drafted the manuscript. YT participated in the study design, coordinated the research activities, and drafted the manuscript. TY participated in the cardiorespiratory and metabolic response measurement and drafted the manuscript. MY participated in the study design, coordinated the research activities, and drafted the manuscript. HK participated in the study design, coordinated the research activities, and drafted the manuscript. All authors read and approved the final manuscript.

\section{Competing interests}

The authors declare that they have no competing interests.

\section{Ethics approval and consent to participate}

This study was approved by the ethical committee of the National Institute of Fitness and Sports in Kanoya. All subjects were informed of the purpose and procedures of the study and possible risks. Written informed consent was obtained from all subjects.

\section{Author details}

${ }^{1}$ Sports and Life Science, National Institute of Fitness and Sports in Kanoya, 1 Shiromizu, Kanoya, Kagoshima 891-2393, Japan. ${ }^{2}$ Japan Institute of Sports Sciences, 3-15-1 NishigaokaKita-ku, Tokyo 115-0056, Japan.

Received: 22 September 2016 Accepted: 16 January 2017

Published online: 08 February 2017

\section{References}

1. Garber CE, Blissmer B, Deschenes MR, Franklin BA, Lamonte MJ, Lee IM, Nieman DC, Swain DP. American College of Sports Medicine position stand. Quantity and quality of exercise for developing and maintaining cardiorespiratory, musculoskeletal, and neuromotor fitness in apparently healthy adults: guidance for prescribing exercise. Med Sci Sports Exerc. 2011;43:1334-59.

2. Miyamoto T, Kamada H, Tamaki A, Moritani T. Low-intensity electrical muscle stimulation induces significant increases in muscle strength and cardiorespiratory fitness. Eur J Sport Sci. 2016: 1-7. doi:10.1080/17461391. 2016.1151944

3. Davis JA. Anaerobic threshold: review of the concept and directions for future research. Med Sci Sports Exerc. 1985;17:6-21.

4. Simoes RP, Mendes RG, Castello V, Machado HG, Almeida LB, Baldissera V, Catai AM, Arena R, Borghi-Silva A. Heart-rate variability and blood-lactate threshold interaction during progressive resistance exercise in healthy older men. J Strength Cond Res. 2010;24:1313-20.

5. de Sousa NM, Magosso RF, Pereira GB, Leite RD, Arakelian VM, Montagnolli AN, Perez SA, Baldissera V. The measurement of lactate threshold in resistance exercise: a comparison of methods. Clin Physiol Funct Imaging. 2011;31:376-81.

6. de Sousa NM, Magosso RF, Pereira GB, Souza MV, Vieira A, Marine DA, Perez $\mathrm{SE}$, Baldissera V. Acute cardiorespiratory and metabolic responses during resistance exercise in the lactate threshold intensity. Int I Sports Med. 2012;33:108-13.

7. Simoes RP, Castello-Simoes V, Mendes RG, Archiza B, Dos Santos DA, Bonjorno Jr JC, de Oliveira CR, Catai AM, Arena R, Borghi-Silva A. Identification of anaerobic threshold by analysis of heart rate variability during discontinuous dynamic and resistance exercise protocols in healthy older men. Clin Physiol Funct Imaging. 2014:34:98-108.

8. Garnacho-Castano MV, Dominguez R, Mate-Munoz JL. Understanding the meaning of lactate threshold in resistance exercises. Int J Sports Med. 2015;36:371-7.

9. Beneke R, Hutler M, Leithauser RM. Maximal lactate-steady-state independent of performance. Med Sci Sports Exerc. 2000;32:1135-9.

10. Billat $\mathrm{VL}$, Sirvent $P, P y G$, Koralsztein JP, Mercier J. The concept of maximal lactate steady state: a bridge between biochemistry, physiology and sport science. Sports Med. 2003;33:407-26.

11. Fujita E, Kanehisa H, Yoshitake Y, Fukunaga T, Nishizono H. Association between knee extensor strength and EMG activities during squat movement. Med Sci Sports Exerc. 2011;43:2328-34.

12. Nakamoto H, Yoshitake $Y$, Takai $Y$, Kanehisa H, Kitamura T, Kawanishi M, Mori S. Knee extensor strength is associated with Mini-Mental State Examination scores in elderly men. Eur J Appl Physiol. 2012;112:1945-53.

13. Takai Y, Fukunaga Y, Fujita E, Mori H, Yoshimoto T, Yamamoto M, Kanehisa $\mathrm{H}$. Effects of body mass-based squat training in adolescent boys. J Sports Sci Med. 2013;12:60-5.

14. Yoshimoto T, Takai Y, Fukunaga Y, Fujita E, Yamamoto M, Kanehisa H. Effects of school-based squat training in adolescent girls. J Sports Med Phys Fitness. 2016;56:678-83.

15. Isear Jr JA, Erickson JC, Worrell TW. EMG analysis of lower extremity muscle recruitment patterns during an unloaded squat. Med Sci Sports Exerc. 1997;29:532-9. 
16. James FW, Kaplan S, Glueck CJ, Tsay JY, Knight MJ, Sarwar CJ. Responses of normal children and young adults to controlled bicycle exercise. Circulation. 1980;61:902-12.

17. Thompson PD, Arena R, Riebe D, Pescatello LS. ACSM's new preparticipation health screening recommendations from ACSM's guidelines for exercise testing and prescription, ninth edition. Curr Sports Med Rep. 2013;12:215-7.

18. Mokaya FO, Nguyen B, Kuo C, Jacobson Q, Rowe A, Zhang P. MARS: a muscle activity recognition system enabling self-configuring musculoskeletal sensor networks. Proceedings of the 12th international conference on Information processing in sensor networks. Philadelphia; 2013.

19. Ozyener F, Rossiter HB, Ward SA, Whipp BJ. Oxygen uptake kinetics during incremental- and decremental-ramp cycle ergometry. J Sports Sci Med. 2011;10:584-9.

20. O'Connell ER, Thomas PC, Cady LD, Karwasky RJ. Energy costs of simulated stair climbing as a job-related task in fire fighting. J Occup Med. 1986;28:282-4

21. Ainsworth BE, Haskell WL, Herrmann SD, Meckes N, Bassett Jr DR, TudorLocke C, Greer JL, Vezina J, Whitt-Glover MC, Leon AS. 2011 Compendium of Physical Activities: a second update of codes and MET values. Med Sci Sports Exerc. 2011;43:1575-81.

22. Orr GW, Green HJ, Hughson RL, Bennett GW. A computer linear regression model to determine ventilatory anaerobic threshold. J Appl Physiol Respir Environ Exerc Physiol. 1982;52:1349-52.

23. Wasserman K, Mcllroy MB. Detecting the threshold of anaerobic metabolism in cardiac patients during exercise. Am J Cardiol. 1964;14:844-52.

24. Tillin NA, Pain MT, Folland JP. Short-term training for explosive strength causes neural and mechanical adaptations. Exp Physiol. 2012;97:630-41.

25. Fleiss J. The design and analysis of clinical experiments. Wiley; 1986.

26. Cohen J. Statistical power analysis for the behavioral science. Hillsdale (NJ): Lawrence Erlbaum Associates; 1988. p. 55-7.

27. Wasserman K, Whipp BJ, Koyal SN, Cleary MG. Effect of carotid body resection on ventilatory and acid-base control during exercise. J Appl Physiol. 1975;39:354-8.

28. Simon J, Young JL, Blood DK, Segal KR, Case RB, Gutin B. Plasma lactate and ventilation thresholds in trained and untrained cyclists. J Appl Physiol. 1986;60:777-81.

29. Meyer T, Gorge G, Schwaab B, Hildebrandt K, Walldorf J, Schafer C, Kindermann I, Scharhag J, Kindermann W. An alternative approach for exercise prescription and efficacy testing in patients with chronic heart failure: a randomized controlled training study. Am Heart J. 2005;149:e1-7.

30. Jette M, Sidney K, Blumchen G. Metabolic equivalents (METS) in exercise testing, exercise prescription, and evaluation of functional capacity. Clin Cardiol. 1990;13:555-65.

31. Hoppeler H, Howald H, Conley K, Lindstedt SL, Claassen H, Vock P, Weibel ER. Endurance training in humans: aerobic capacity and structure of skeletal muscle. J Appl Physiol. 1985;59:320-7.

32. Henriksson J, Bonde-Petersen F. Integrated electromyography of quadriceps femoris muscle at different exercise intensities. J Appl Physiol. 1974;36:218-20.

33. Arendt-Nielsen L, Mills KR. Muscle fibre conduction velocity, mean power frequency, mean EMG voltage and force during submaximal fatiguing contractions of human quadriceps. Eur J Appl Physiol Occup Physiol. 1988;58:20-5.

34. Takai Y, Sawai S, Kanehisa H, Kawakami Y, Fukunaga T. Age and sex differences in the levels of muscular activities during daily physical actions. Int J Sports Health Sci. 2008;6:169-81.

\section{Submit your next manuscript to BioMed Central and we will help you at every step:}

- We accept pre-submission inquiries

- Our selector tool helps you to find the most relevant journal

- We provide round the clock customer support

- Convenient online submission

- Thorough peer review

- Inclusion in PubMed and all major indexing services

- Maximum visibility for your research

Submit your manuscript at www.biomedcentral.com/submit
Biomed Central 